\title{
PENGARUH KOMPOSISI DAN BAHAN MEDIA TERHADAP PERTUMBUHAN SEMAI PINUS (Pinus merkusii)
}

\author{
The Effect of Composition and Materials of Medium on the Growth \\ of Pinus merkusii Seedlings \\ Suryo Hardiwinoto, Handojo H. Nurjanto, Agung W. Nugroho dan/and Widiyatno \\ Fakultas Kehutanan Universitas Gadjah Mada, Bulaksumur Yogyakarta \\ Telp. 0274-584136, Fax. 0274-550541 \\ Email: suryohardiwinoto@yahoo.com
}

Naskah masuk : 2 Maret 2010; Naskah diterima : 10 Desember 2010

\begin{abstract}
Physical and chemical properties of the medium, especially porosity and nutrients availability, are required to produce good quality seedlings of pine (Pinus merkusii Jungh et de Vries). Fresh leaves and leaf litter of pine could potentially be used to produce medium which meet those requirements. The objective of this research was to clarify the effect of composition and materials of medium on the growth of pine seedlings. The experiment used a factorial randomized block design with two factors and three blocks as replications. The first factor (A) was pine leaf materials, i.e. coarsely ground fresh leaves, coarsely ground leaf litter and finely ground leaf litter. The second factor $(B)$ was composition of organic fertilizer (cow dung) and soil, i.e. each $45 \%, 35 \%, 25 \%$ and $15 \%$. Nested analysis of variance was used to analyze the obtained data. Parameters measured were $N$ content and $C / N$ ratio of the medium, and growth of the seedlings. The highest seedling growth of pine was obtained at the composition medium of $35 \%$ organic fertilizer, 35\% soil and 30\% coarsely ground fresh leaves $\left(B_{2} A_{3}\right)$. The material of coarsely ground fresh leaves had the highest $N$ content and the lowest $C / N$ ratio, and it had highest seedlings growth. The medium composition of $B_{2} A_{3}$ was recommended to be used as growth medium to produce pine seedlings.
\end{abstract}

Keywords: Leaf materials, medium composition, pine, seedling growth

\begin{abstract}
ABSTRAK
Sifat fisika-kimia media tumbuh, khususnya porositas dan ketersediaan nutrisi diperlukan untuk memproduksi semai pinus (Pinus merkusii Jungh et de Vries) yang berkualitas. Daun segar dan seresah daun pinus dapat digunakan sebagai media tumbuh yang dapat memenuhi persyaratan yang dimaksud. Penelitian ini dilakukan dengan tujuan untuk mengetahui pengaruh komposisi dan bahan media terhadap pertumbuhan semai pinus. Penelitian ini merupakan percobaan faktorial dengan rancangan acak lengkap berblok, dengan dua faktor dan tiga blok sebagai ulangan. Faktor pertama adalah bahan daun pinus (A) yaitu: daun segar kasar, seresah daun kasar dan seresah daun halus. Faktor kedua adalah aras pupuk organik dan tanah (B), yaitu masing-masing dengan aras: 45\%, 35\%, 25\% dan 15\%. Analisis varians bersarang digunakan untuk menganalisis data yang diperoleh. Parameter yang diukur adalah kandungan $\mathrm{N}$, nisbah $\mathrm{C} / \mathrm{N}$ media tumbuh serta pertumbuhan tinggi dan diameter semai pinus. Pertumbuhan semai pinus terbaik didapatkan melalui komposisi media dengan perlakuan $35 \%$ pupuk organik, $35 \%$ tanah dan $30 \%$ daun segar kasar $\left(\mathrm{B}_{2} \mathrm{~A}_{3}\right)$. Bahan daun segar kasar mempunyai kandungan $\mathrm{N}$ tertinggi dan nisbah $\mathrm{C} / \mathrm{N}$ terendah, serta menghasilkan pertumbuhan semai terbaik. Komposisi media $\mathrm{B}_{2} \mathrm{~A}_{3}$ direkomendasikan sebagai media tumbuh untuk memproduksi semai pinus.
\end{abstract}

Kata kunci: Bahan daun, komposisi media, pinus, pertumbuhan semai 


\section{PENDAHULUAN}

Pinus (Pinus merkusii Jungh et de Vries) merupakan jenis tumbuhan asli Indonesia dengan sebaran alam di daerah Sumatera. Menurut Butarbutar dkk. (1998), di daerah Sumatera tegakan pinus alam dibagi menjadi 3 strain, yaitu strain Aceh, Tapanuli dan Kerinci. Pinus tidak menuntut syarat yang tinggi terhadap tanah, dapat tumbuh pada daerah yang kurang subur dan ketinggian tempat 1.000-1.500 meter di atas permukaan laut (Soekotjo, 1977), serta dapat mencapai tinggi pohon antara 20-40 meter (Tantra, 1981). Kayu pinus mempunyai kualitas yang cukup baik untuk berbagai tujuan. Harahap (1999) menyebutkan bahwa pinus mempunyai kegunaan ganda seperti untuk bahan baku pulp dan kertas, terpentin, pensil dan kayu pertukangan. Pinus juga merupakan jenis yang mampu menghasilkan getah dengan nilai ekonomi yang tinggi.

Hutan tanaman pinus telah lama dikembangkan di Indonesia khususnya di Jawa oleh Perum Perhutani. Saat ini pinus merupakan jenis tanaman hutan terluas ke dua setelah jati yang diusahakan oleh Perum Perhutani. Dilaporkan oleh Hardiwinoto dkk. (1994) bahwa seresah daun pinus mempunyai kandungan lignin dan selulose yang tinggi sehingga proses dekomposisinya berjalan sangat lambat dibandingkan dengan seresah daun jenis lain. Seresah daun pinus yang melimpah dapat menutup lantai hutan dan meningkatkan kemasaman tanah sehingga tidak mudah bagi jenis lain untuk dapat tumbuh dan berkembang di dalam tegakan pinus. Daun pinus merupakan bahan organik yang mempunyai potensi untuk dimanfaatkan sebagai media pertumbuhan semai.

Penanaman pinus dalam skala luas memerlukan bibit bermutu dalam jumlah besar dengan tata waktu yang tepat. Untuk meningkatkan mutu bibit pinus, Perum Perhutani telah mengembangkan media pembibitan dalam root-trainer berupa single-tube yang dapat mendukung pertumbuhan bibit pinus karena mempunyai bentuk yang sesuai dengan kondisi perakaran pinus. Media untuk pembuatan semai pinus menggunakan single-tube harus memenuhi beberapa persyaratan, antara lain media harus mempunyai sifat fisik-kimia yang baik dan keberadaan bahan bakunya melimpah.

Secara fisik, media harus mempunyai porositas yang tinggi, drainase dan aerasi yang baik. Hal ini akan dapat mendukung metabolisme dan pertumbuhan akar yang baik sehingga dapat dihasilkan semai dengan perakaran yang kompak. Media dengan porositas tinggi juga akan dapat menghasilkan bibit dalam kontainer yang ringan sehingga memudahkan pada waktu diangkut. Secara kimia, media tumbuh semai juga harus mampu menyediakan unsur hara yang diperlukan bagi pertumbuhan dan perkembangan semai, khususnya unsur hara makro yang diperlukan tanaman dalam jumlah besar, yaitu N, $\mathrm{P}, \mathrm{K}, \mathrm{Ca}, \mathrm{Mg}$, dan S. Media untuk memproduksi semai pinus dengan menggunakan single-tube harus ringan, kompak, mengandung unsur hara yang diperlukan, dan mudah diperoleh. Media yang memenuhi persyaratan tersebut pada umumnya adalah bahan organik seperti kompos daun atau bahan organik lain. Sehubungan dengan hal tersebut maka penelitian tentang pengaruh komposisi dan bahan media semai menjadi penting untuk dilaksanakan. Penelitian ini dilaksanakan dengan tujuan untuk mengetahui pengaruh komposisi dan bahan media terhadap pertumbuhan semai pinus.

\section{METODE PENELITIAN}

Bahan-bahan yang digunakan dalam penelitian ini adalah: pupuk organik berupa pupuk kandang sapi, top-soil yang diambil dari bawah tegakan pinus di Baturaden serta daun segar dan seresah daun pinus. Alat-alat yang digunakan dalam penelitian ini adalah: pencacah bahan organik, bak pengomposan ukuran $60 \times 45$ x $60 \mathrm{~cm}$, sekop, single-tube, timbangan, ayakan, bak tabur ukuran $50 \times 30 \times 10 \mathrm{~cm}$, rak tempat kontiner, sprayer, serta alat pengukur tinggi dan diamater semai.

Rancangan yang digunakan untuk penelitian uji komposisi media berbahan baku pupuk organik, tanah dan daun pinus adalah percobaan faktorial dengan Rancangan Acak Lengkap Berblok (RCBD = Randomized Completely Block Design). Dua faktor yang digunakan dalam penelitian adalah sebagai berikut:

Faktor 1 : bahan media daun pinus:

$A_{1}$ : Seresah daun halus (lolos saring dengan ukuran lubang ayakan 2 x 2 $\mathrm{mm}$ );

$\mathrm{A}_{2}$ : Seresah daun kasar (panjang $\pm 1 \mathrm{~cm}$ ); dan

$\mathrm{A}_{3}$ : Daun segar kasar (panjang $\pm 1 \mathrm{~cm}$ ) 
Faktor 2: Aras campuran media dari pupuk organik/pupuk kandang $(\mathrm{P})$ dan tanah bermikorisa $(\mathrm{T})$ :

$$
\begin{array}{ll}
\mathrm{B}_{1}: 45 \% \mathrm{P}+45 \% \mathrm{~T} ; & \mathrm{B}_{2}: 35 \% \mathrm{P}+35 \% \mathrm{~T} ; \\
\mathrm{B}_{3}: 25 \% \mathrm{P}+25 \% \mathrm{~T} ; & \mathrm{B}_{4}: 15 \% \mathrm{P}+15 \% \mathrm{~T}
\end{array}
$$

Penelitian ini dilaksanakan dengan menggunakan 3 blok sebagai ulangan, dan pada setiap blok terdapat 12 perlakuan yang merupakan kombinasi B dengan A sedemikian rupa sehingga jumlahnya $100 \%$ sebagai berikut:

$\mathrm{B}_{1} \mathrm{~A}_{1}: 45 \% \mathrm{P}+45 \% \mathrm{~T}+10 \%$ seresah daun halus

$\mathrm{B}_{1} \mathrm{~A}_{2}: 45 \% \mathrm{P}+45 \% \mathrm{~T}+10 \%$ seresah daun kasar

$\mathrm{B}_{1} \mathrm{~A}_{3}: 45 \% \mathrm{P}+45 \% \mathrm{~T}+10 \%$ daun segar kasar

$\mathrm{B}_{2} \mathrm{~A}_{1}: 35 \% \mathrm{P}+35 \% \mathrm{~T}+30 \%$ seresah daun halus

$\mathrm{B}_{2} \mathrm{~A}_{2}: 35 \% \mathrm{P}+35 \% \mathrm{~T}+30 \%$ seresah daun kasar

$\mathrm{B}_{2} \mathrm{~A}_{3}: 35 \% \mathrm{P}+35 \% \mathrm{~T}+30 \%$ daun segar kasar

$\mathrm{B}_{3} \mathrm{~A}_{1}: 25 \% \mathrm{P}+25 \% \mathrm{~T}+50 \%$ seresah daun halus

$\mathrm{B}_{3} \mathrm{~A}_{2}: 25 \% \mathrm{P}+25 \% \mathrm{~T}+50 \%$ seresah daun kasar

$\mathrm{B}_{3} \mathrm{~A}_{3}: 25 \% \mathrm{P}+25 \% \mathrm{~T}+50 \%$ daun segar kasar

$\mathrm{B}_{4} \mathrm{~A}_{1}: 15 \% \mathrm{P}+15 \% \mathrm{~T}+70 \%$ seresah daun halus

$\mathrm{B}_{4} \mathrm{~A}_{2}: 15 \% \mathrm{P}+15 \% \mathrm{~T}+70 \%$ seresah daun kasar

$\mathrm{B}_{4} \mathrm{~A}_{3}: 15 \% \mathrm{P}+15 \% \mathrm{~T}+70 \%$ daun segar kasar

Media dengan berbagai komposisi bahan tersebut dikomposkan selama 3 bulan dalam bak pengomposan. Analisis kandungan unsur hara $\mathrm{N}$ dan nisbah $\mathrm{C} / \mathrm{N}$ media sebelum digunakan dilakukan di Laboratorium Ilmu Tanah Hutan Fakultas Kehutanan Universitas Gadjah Mada.
Penyiapan semai dilakukan dengan menebar benih pinus dalam bak tabur. Perkecambahan benih berlangsung dalam waktu sekitar 2 minggu, selanjutnya dilakukan penyapihan kecambah ke dalam single-tube yang telah diisi media sesuai dengan rancangan komposisi yang telah ditentukan. Pada masing-masing perlakuan terdapat 30 semai, sehingga jumlah seluruh semai yang digunakan dalam penelitian ini $=30 \times 12 \times 3$ $=1080$ semai. Pengukuran tinggi dan diameter semai dilakukan pada saat semai berumur 4 bulan. Data yang diperoleh dianalisis secara statistik dengan analisis varian bersarang (Nested Analysis of Variance) dan apabila terdapat perbedaan yang nyata diantara perlakuan yang diujikan maka dilanjutkan dengan uji DMRT (Duncan Multiple Range Test). Untuk mengetahui hubungan antara kandungan hara $\mathrm{N}$ dan nisbah $\mathrm{C} / \mathrm{N}$ dengan parameter pertumbuhan semai dilakukan analisis regresi-korelasi.

\section{HASIL DAN PEMBAHASAN}

Hasil analisis varian bersarang terhadap parameter tinggi semai pada berbagai perlakuan disajikan pada Tabel 1. Analisis varian menunjukkan bahwa aras pupuk organik dan tanah serta komposisi media memberikan pengaruh yang nyata terhadap pertumbuhan tinggi semai pada taraf uji 0,01 ; untuk itu

\begin{tabular}{|c|c|c|c|c|c|}
\hline $\begin{array}{c}\text { Sumber variasi } \\
\text { (Source of variation) }\end{array}$ & $\begin{array}{l}\mathrm{Db} \\
(D f)\end{array}$ & $\begin{array}{l}\text { Jumlah } \\
\text { kuadrat } \\
\text { (Sum } \\
\text { square) }\end{array}$ & $\begin{array}{l}\text { Kuadrat } \\
\text { tengah } \\
\text { (Mean } \\
\text { square) }\end{array}$ & $\begin{array}{l}\text { F Hitung } \\
(F \text { calc. })\end{array}$ & $\operatorname{Pr}>F$ \\
\hline Blok (Block) & 2 & 2,0913 & 1,0456 & $3,11 \mathrm{~ns}$ & 0,0645 \\
\hline $\begin{array}{l}\text { Aras pupuk organik dan tanah } \\
\text { (Dosage of organic fertilizer and } \\
\text { soil) (B) }\end{array}$ & 3 & 8,0048 & 2,6683 & $7,95 * *$ & 0,0009 \\
\hline $\begin{array}{l}\text { Komposisi media: Bahan daun (A) } \\
\text { bersarang dalam B (Media } \\
\text { composition: Leaf materials }(A) \\
\text { Nested within B) }\end{array}$ & 8 & 20,7816 & 2,5977 & $7,73 * *$ & $<0,0001$ \\
\hline Galat (Error) & 22 & 7,3885 & 0,3358 & & \\
\hline Total (Total) & 35 & 38,2663 & & & \\
\hline
\end{tabular}
dilakukan uji DMRT yang hasilnya disajikan

Tabel (Table) 1. Analisis varian bersarang terhadap parameter tinggi semai (Nested variance analysis on the seedling height)

Keterangan (Notes): ** berbeda nyata pada taraf uji 0,05 dan 0,01 (significantly different at 0.05 and 0.01 ) ns tidak berbeda nyata pada taraf uji 0,05 (not significantly different at 0.05) 
Tabel(Table) 2. Hasil uji DMRT komposisi media: bahan daun (A) bersarang dalam aras (B) pupuk organik $(\mathrm{P})$ dan tanah $(\mathrm{T})$ terhadap tinggi $(\mathrm{cm})$ semai (Duncan test results of media composition: leaf materials $(A)$ nested within organic fertilizer $(P)$ and soil $(T)$ dosage (B) on the height ( $\mathrm{cm}$ ) of pine seedlings)

\begin{tabular}{|c|c|c|c|c|c|}
\hline \multirow{3}{*}{$\begin{array}{c}\text { Bahan } \\
\text { (Materials) }\end{array}$} & \multirow{2}{*}{\multicolumn{4}{|c|}{$\begin{array}{c}\text { Aras pupuk organik }(\mathrm{P}) \text { dan tanah }(\mathrm{T}) \\
\text { (Dosage of organic fertilizer }(P) \text { and Soil }(T)\end{array}$}} & \multirow{3}{*}{$\begin{array}{c}\text { Rerata } \\
\text { (Average) }\end{array}$} \\
\hline & & & & & \\
\hline & $\begin{array}{c}45 \% \mathrm{P} \\
45 \% \mathrm{~T} \\
\left(\mathrm{~B}_{1}\right)\end{array}$ & $\begin{array}{c}35 \% \mathrm{P} \\
35 \% \mathrm{~T} \\
\left(\mathrm{~B}_{2}\right)\end{array}$ & $\begin{array}{c}25 \% \mathrm{P} \\
25 \% \mathrm{~T} \\
\left(\mathrm{~B}_{3}\right)\end{array}$ & $\begin{array}{c}15 \% \mathrm{P} \\
15 \% \mathrm{~T} \\
\left(\mathrm{~B}_{4}\right)\end{array}$ & \\
\hline $\begin{array}{l}\text { Seserah daun halus } \\
\text { (Finely ground leaf litter) }\left(\mathrm{A}_{1}\right)\end{array}$ & $\begin{array}{l}9,15 \\
b\end{array}$ & $\begin{array}{l}9,68 \\
\mathrm{ab}\end{array}$ & $\begin{array}{c}7,09 \\
\mathrm{c}\end{array}$ & $\begin{array}{c}7,44 \\
\mathrm{c}\end{array}$ & 8.34 \\
\hline $\begin{array}{l}\text { Seserah daun kasar (Coarsely ground } \\
\text { leaf litter) }\left(\mathrm{A}_{2}\right)\end{array}$ & $\begin{array}{c}9,68 \\
a b\end{array}$ & $\begin{array}{c}9,53 \\
\mathrm{ab}\end{array}$ & $\begin{array}{c}9,41 \\
\mathrm{ab}\end{array}$ & $\begin{array}{c}8,90 \\
b\end{array}$ & 9.38 \\
\hline $\begin{array}{l}\text { Daun segar kasar (Coarsely ground } \\
\text { fresh leaves) }\left(\mathrm{A}_{3}\right)\end{array}$ & $\begin{array}{c}9,25 \\
\mathrm{ab}\end{array}$ & $\begin{array}{c}10,12 \\
\mathrm{a}\end{array}$ & $\begin{array}{c}9,93 \\
\mathrm{a}\end{array}$ & $\begin{array}{l}9,36 \\
\mathrm{ab}\end{array}$ & 9.66 \\
\hline Rerata (Mean) & $\begin{array}{c}9,36 \\
\mathrm{ab}\end{array}$ & $\begin{array}{c}9,78 \\
\mathrm{a}\end{array}$ & $\begin{array}{c}8,81 \\
\text { bc }\end{array}$ & $\begin{array}{c}8,57 \\
\mathrm{c}\end{array}$ & \\
\hline
\end{tabular}

Keterangan(Notes): Angka yang diikuti huruf sama menunjukkan tidak adanya perbedaan yang nyata pada taraf uji 0,05 (Figures followed by the same letter are not significantly different at 0.05)

Hasil uji lanjut dengan menggunakan Duncan Multiple Range Test (DMRT) dalam Tabel 2 menunjukkan bahwa komposisi media dengan menggunakan $35 \%$ Pupuk organik $+35 \%$ Tanah $+30 \%$ bahan daun segar kasar $\left(\mathrm{B}_{2} \mathrm{~A}_{3}\right)$ memberikan pertumbuhan tinggi terbaik, dengan rerata tinggi $10,12 \mathrm{~cm}$; dan diikuti oleh $\mathrm{B}_{3} \mathrm{~A}_{3}$ dengan rerata tinggi $9,92 \mathrm{~cm}$. Pertumbuhan tinggi tersebut jauh lebih baik dibandingkan dengan komposisi media $\mathrm{B}_{3} \mathrm{~A}_{1}$ atau $\mathrm{B}_{4} \mathrm{~A}_{1}$ yang masing-masing mempunyai tinggi rata-rata sebesar 7,08 $\mathrm{cm}$ dan 7,44 cm. Data tersebut menunjukkan bahwa penambahan aras pupuk organik dan tanah masing-masing 15\%, 25\% diikuti dengan pertambahan rerata tinggi semai, mencapai rerata tinggi maksimum pada aras $35 \%$, dan mulai menurun pada aras $45 \%$. Bahan media daun segar kasar $\left(\mathrm{A}_{3}\right)$ memberikan rerata pertumbuhan tinggi yang terbaik $(9,66 \mathrm{~cm})$ dibandingkan dengan seresah daun $\operatorname{kasar}\left(\mathrm{A}_{2}\right)$ dan seresah daun halus $\left(A_{1}\right)$ yang masing-masing mempunyai rerata tinggi 9,38 dan $8,34 \mathrm{~cm}$.

Analisis varians bersarang perlakuan aras (B) pupuk organik dan tanah serta komposisi media bahan daun (A) bersarang dalam B terhadap pertumbuhan diameter dapat dilihat pada Tabel 3.

Tabel (Table) 3. Analisis varian bersarang terhadap parameter diameter semai (Nested variance analysis on the seedling diameter)

\begin{tabular}{|l|c|c|c|c|c|}
\hline \multicolumn{1}{|c|}{$\begin{array}{c}\text { Sumber Variasi } \\
\text { (Source of Variation) }\end{array}$} & $\begin{array}{c}\text { Db } \\
(\text { Df) }\end{array}$ & $\begin{array}{c}\text { Jumlah } \\
\text { kuadrat } \\
\text { (Sum } \\
\text { square) }\end{array}$ & $\begin{array}{l}\text { Kuadrat } \\
\text { tengah } \\
\text { (Mean } \\
\text { square) }\end{array}$ & $\begin{array}{c}\text { F Hitung } \\
\text { (F calc.) }\end{array}$ & Pr > F \\
\hline Blok (Block) & 2 & 0,0464 & 0,0232 & $4,55^{*}$ & 0,0222 \\
\hline $\begin{array}{l}\text { Aras pupuk organik dan tanah } \\
\text { (Dosage of organic fertilizer and } \\
\text { soil) (B) }\end{array}$ & 3 & 0,0201 & 0,0067 & $1,31 \mathrm{~ns}$ & 0,2949 \\
\hline $\begin{array}{l}\text { Komposisi media: Bahan Daun (A) } \\
\text { bersarang dalam B (Media } \\
\text { composition: Leaf materials (A) } \\
\text { Nested within B) }\end{array}$ & 8 & 0,2177 & 0,0272 & $5,34^{* *}$ & 0,0008 \\
\hline \multicolumn{1}{c|}{ Galat } & 22 & 0,1121 & 0,0051 & & \\
\hline Total & 35 & 0,3963 & & & \\
\hline
\end{tabular}

Keterangan (Notes): ** berbeda nyata pada taraf uji 0,05 dan 0,01 (significantly different at 0.05 and 0.01 )

* berbeda nyata pada taraf uji 0,05 ( significantly different at 0.05 and 0.01 )

ns tidak berbeda nyata pada taraf uji 0,05 (not significantly different at 0.05) 
Dari hasil analisis varians bersarang pada Tabel 3 dapat diketahui bahwa komposisi media: perlakuan A bersarang dalam perlakuan B memberi pengaruh yang nyata terhadap pertumbuhan diameter pada taraf uji 0,01 . Untuk mengetahui komposisi media yang memberi pengaruh nyata terhadap pertumbuhan diameter maka dilakukan uji DMRT yang hasilnya disajikan dalam Tabel 4.

Tabel(Table) 4. Hasil uji DMRT komposisi media: bahan daun (A) bersarang dalam aras (B) pupuk organik $(\mathrm{P})$ dan tanah $(\mathrm{T})$ terhadap diameter $(\mathrm{mm})$ semai (Duncan test results of media composition: leaf materials $(A)$ nested within organic fertilizer $(P)$ and soil $(T)$ dosage (B) on the diameter ( $\mathrm{mm}$ ) of pine seedlings)

\begin{tabular}{|c|c|c|c|c|c|}
\hline \multirow[b]{2}{*}{$\begin{array}{c}\text { Bahan } \\
\text { (Materials) }\end{array}$} & \multicolumn{4}{|c|}{$\begin{array}{c}\text { Aras pupuk organik }(\mathrm{P}) \text { dan tanah }(\mathrm{T}) \\
\text { (Dosage of organic fertilizer }(P) \text { and Soil }(T)\end{array}$} & \multirow[b]{2}{*}{$\begin{array}{l}\text { Rerata } \\
\text { (Average) }\end{array}$} \\
\hline & $\begin{array}{c}45 \% \mathrm{P} \\
45 \% \mathrm{~T} \\
\left(\mathrm{~B}_{1}\right)\end{array}$ & $\begin{array}{c}35 \% \mathrm{P} \\
35 \% \mathrm{~T} \\
\left(\mathrm{~B}_{2}\right)\end{array}$ & $\begin{array}{c}25 \% \mathrm{P} \\
25 \% \mathrm{~T} \\
\left(\mathrm{~B}_{3}\right)\end{array}$ & $\begin{array}{c}15 \% \mathrm{P} \\
15 \% \mathrm{~T} \\
\left(\mathrm{~B}_{4}\right)\end{array}$ & \\
\hline $\begin{array}{l}\text { Seserah daun halus } \\
\text { (Finely ground leaf litter) }\left(\mathrm{A}_{1}\right)\end{array}$ & $\begin{array}{c}1,17 \\
\mathrm{ab}\end{array}$ & $\begin{array}{c}1,14 \\
b c\end{array}$ & $\begin{array}{c}1,00 \\
\mathrm{c}\end{array}$ & $\begin{array}{c}1,03 \\
b c\end{array}$ & 1,08 \\
\hline $\begin{array}{l}\text { Seserah daun kasar (Coarsely ground } \\
\text { leaf litter) }\left(\mathrm{A}_{2}\right)\end{array}$ & $\begin{array}{c}1,14 \\
\mathrm{bc}\end{array}$ & $\begin{array}{c}1,14 \\
\mathrm{bc}\end{array}$ & $\begin{array}{c}1,16 \\
b\end{array}$ & $\begin{array}{l}1,17 \\
\mathrm{ab}\end{array}$ & 1,15 \\
\hline $\begin{array}{l}\text { Daun segar kasar (Coarsely ground } \\
\text { fresh leaves) }\left(\mathrm{A}_{3}\right)\end{array}$ & $\begin{array}{c}1,15 \\
b\end{array}$ & $\begin{array}{c}1,30 \\
\mathrm{a}\end{array}$ & $\begin{array}{c}1,22 \\
\mathrm{ab}\end{array}$ & $\begin{array}{c}1,26 \\
\mathrm{a}\end{array}$ & 1,23 \\
\hline Rerata $($ Mean $)$ & 1,16 & 1,19 & 1,12 & 1,16 & \\
\hline
\end{tabular}

Keterangan(Notes): Angka yang diikuti huruf sama menunjukkan tidak adanya perbedaan yang nyata pada taraf uji 0,05 (Figures followed by the same letter are not significantly different at 0.05)

Tabel 4 menunjukkan bahwa komposisi media dengan perlakuan $\mathrm{B}_{2} \mathrm{~A}_{3} \quad(35 \%$ pupuk organik $+35 \%$ tanah $+30 \%$ daun segar kasar) mempunyai rerata diameter yang paling besar yaitu $1,30 \mathrm{~mm}$, diikuti perlakuan $\mathrm{B}_{4} \mathrm{~A}_{3}$ dengan diameter $1,26 \mathrm{~mm}$, dan $\mathrm{B}_{3} \mathrm{~A}_{3}$ dengan diameter $1,22 \mathrm{~mm}$; sedang yang paling kecil pertumbuhan diameternya adalah perlakuan B4A1 $(15 \% \mathrm{P}+$ $15 \% \mathrm{~T}+70 \%$ seresah daun halus) dengan rerata diameter sebesar $1,03 \mathrm{~mm}$ dan perlakuan $\mathrm{B}_{3} \mathrm{~A}_{1}$ $(25 \% \mathrm{P}+25 \% \mathrm{~T}+50 \%$ seresah daun halus $)$ dengan diameter $1,00 \mathrm{~mm}$. Seperti pada pertumbuhan tinggi, bahan media daun segar kasar $\left(\mathrm{A}_{3}\right)$ memberikan rerata pertumbuhan tinggi yang terbaik $(1,23 \mathrm{~mm})$ dibandingkan dengan seresah daun kasar $\left(\mathrm{A}_{2}\right)$ dan seresah daun halus $\left(\mathrm{A}_{1}\right)$ yang masing mempunyai rerata tinggi 1,15 dan 1,08 mm. Baker (1950) mengatakan bahwa pertumbuhan suatu jenis pohon dipengaruhi oleh nutrisi, air dan intensitas cahaya matahari. Beberapa faktor luar yang berpengaruh terhadap pertumbuhan tanaman, antara lain adalah: sinar matahari, suhu udara, air dan unsurunsur hara dalam tanah (Hardjowigeno, 1987). Pertumbuhan diameter suatu jenis pohon dikendalikan oleh fotosintesis dan faktor lingkungan (Kramer and Kozlowski, 1979), dan tergantung pada kondisi tempat tumbuh (Daniel et al., 1992).

Penambahan pupuk organik dan tanah telah memberikan pengaruh terhadap pertumbuhan tinggi dan diameter semai. Data pada Tabel 4 menunjukkan bahwa penambahan aras pupuk organik dan tanah masing-masing sebesar $15,25 \%$ diikuti dengan pertambahan rerata tinggi semai, mencapai rerata tinggi maksimum pada aras $35 \%$, dan mulai menurun pada aras $45 \%$. Penambahan pupuk organik (pupuk kandang sapi) sebesar 35\% telah dapat memberikan unsur hara yang cukup dan sifat fisika yang baik sehingga mampu menghasilkan pertumbuhan semai yang terbaik. Rifai dkk. (1981) menjelaskan bahwa pupuk kandang sapi merupakan pupuk dingin dimana proses perombakan bahan organik oleh jasad renik berlangsung secara perlahan-lahan. Pupuk kandang merupakan sumber hara $\mathrm{N}, \mathrm{P}$, dan $\mathrm{K}$ yang amat penting bagi pertumbuhan dan perkembangan semai (Sarief, 1986). Selain itu pupuk kandang mampu memperbaiki struktur tanah menjadi remah, meningkatkan porositas tanah, menjaga kelembaban dan banyak mengandung mikroorganisme yang mampu 
mensintetis senyawa-senyawa tertentu yang berguna bagi pertumbuhan semai. Dengan mempunyai fungsi dapat memperbaiki sifat fisik, kimia dan biologi tanah yang baik maka pupuk organik dapat mendorong perkembangan perakaran yang lebih luas sehingga pertumbuhan tanaman dapat meningkat.

Soepardi (1979) menyebutkan bahwa penggunaan pupuk kandang yang berlebihan dapat mengakibatkan mikroorganisme dapat berkembang dengan pesat, sehingga $\mathrm{N}$ yang dihasilkan rendah. Penambahan pupuk organik ke dalam media akan dapat menambah ketersediaan unsur hara, karena di dalam pupuk organik terdapat berbagai unsur hara baik unsur hara makro maupun mikro yang sangat berguna bagi pertumbuhan tanaman (Sutejo, 1992). Pupuk kandang selain mengandung unsur hara makro dan mikro juga mengandung berbagai mikroorganisme yang dapat membantu proses dekomposisi bahan organik (Sutejo dan Kartasapoetra, 1991). Pupuk kandang dapat memperbaiki kondisi dan struktur tanah, meningkatkan daya serap tanah terhadap air, meningkatkan kondisi lingkungan kehidupan mikroorganisme dan mengandung berbagai unsur hara (Buckman and Brady, 1969).

Penambahan tanah yang diambil dari bawah tegakan pinus di Baturaden ke dalam media diharapkan telah mengandung mikorisa. Fakuara (1988) menyatakan bahwa akar yang bermikorisa mengeluarkan enzim yang dapat menguraikan unsur $\mathrm{P}$ tak tersedia menjadi tersedia. Mikorisa juga merupakan ekstraktor nutrisi yang baik dan dapat menghasilkan $\mathrm{CO}_{2}$ dan asam organik tertentu yang dapat meningkatkan kelarutan tanah sehingga unsur bisa diserap oleh akar (Russel, 1973). Lebih lanjut dikatakan oleh Fakuara (1988), bahwa semai yang bermikorisa akan lebih tahan terhadap penyakit. Hal ini disebabkan oleh adanya hifa yang membungkus akar sehingga mencegah terjadinya infeksi oleh patogen. Suhardi (1990) menjelaskan bahwa mikorisa mampu menghasilkan zat pengatur tumbuh seperti auksin, sitokinin dan giberilin, lebih tahan terhadap kekeringan dan dapat memperbaiki struktur tanah. Penambahan tanah bermikorhiza sebesar 35\% mempunyai peran yang sangat penting dalam mendukung pertumbuhan semai pinus sehingga mencapai tingkat kecepatan tumbuh yang terbaik.

Sebagai bahan organik, daun pinus dapat digunakan sebagai bahan baku media pertumbuhan semai setelah melalui proses dekomposisi dan pengkayaan nutrisi. Hasil analisis kandungan hara $\mathrm{N}$ dan nisbah $\mathrm{C} / \mathrm{N}$ media sebelum digunakan sebagai media tumbuh

Tabel(Table) 5. Kandungan unsur hara $\mathrm{N}$ dan nisbah $\mathrm{C} / \mathrm{N}$ media dengan berbagai komposisi sebelum digunakan (Content of $N$ and $C / N$ ratio in each composition of medium)

\begin{tabular}{|c|c|c|c|c|}
\hline \multirow{2}{*}{ No. } & $\begin{array}{c}\text { Komposisi media } \\
\text { Composition of media) }\end{array}$ & \multicolumn{2}{|c|}{$\begin{array}{c}\text { Kandungan unsur hara } \\
(\text { Nutrient content })\end{array}$} & $\begin{array}{c}\text { Nisbah C/N (C/N } \\
\text { Ratio })\end{array}$ \\
\cline { 3 - 4 } & & $\mathrm{C}(\%)$ & $\mathrm{N}(\%)$ & \\
\hline 1 & $\mathrm{~B}_{1} \mathrm{~A}_{1}$ & 14,70 & 0,74 & 19,91 \\
\hline 2 & $\mathrm{~B}_{2} \mathrm{~A}_{1}$ & 19,05 & 0,61 & 31,40 \\
\hline 3 & $\mathrm{~B}_{3} \mathrm{~A}_{1}$ & 23,57 & 0,70 & 33,67 \\
\hline 4 & $\mathrm{~B}_{4} \mathrm{~A}_{1}$ & 18,67 & 0,43 & 43,33 \\
\hline & Rerata (Mean) $\mathrm{A}_{1}$ & 19,00 & 0,62 & 32,08 \\
\hline & & & & \\
\hline 5 & $\mathrm{~B}_{1} \mathrm{~A}_{2}$ & 15,00 & 0,95 & 15,81 \\
\hline 6 & $\mathrm{~B}_{2} \mathrm{~A}_{2}$ & 17,86 & 0,87 & 20,50 \\
\hline 7 & $\mathrm{~B}_{3} \mathrm{~A}_{2}$ & 20,58 & 0,97 & 21,20 \\
\hline 8 & $\mathrm{~B}_{4} \mathrm{~A}_{2}$ & 13,77 & 0,60 & 22,94 \\
\hline & Rerata $($ Mean $) \mathrm{A}_{2}$ & 16,80 & 0,85 & 20,11 \\
\hline & & & & \\
\hline 9 & $\mathrm{~B}_{1} \mathrm{~A}_{3}$ & 13,30 & 0,79 & 16,79 \\
\hline 10 & $\mathrm{~B}_{2} \mathrm{~A}_{3}$ & 16,76 & 1,07 & 15,67 \\
\hline 11 & $\mathrm{~B}_{3} \mathrm{~A}_{3}$ & 17,74 & 0,98 & 18,19 \\
\hline 12 & $\mathrm{~B}_{4} \mathrm{~A}_{3}$ & 21,14 & 1,15 & 18,41 \\
\hline & Rerata $($ Mean $) \mathrm{A}_{3}$ & 17,24 & 1,00 & 17,24 \\
\hline
\end{tabular}


Tabel 5 menunjukkan bahwa rerata kandungan unsur hara $\mathrm{N}$ pada media dengan bahan seresah daun pinus halus $\left(\mathrm{A}_{1}\right)$ mempunyai nilai terendah dan nisbah $\mathrm{C} / \mathrm{N}$ tertinggi, yaitu $0,62 \%$ dan 32,08. Kandungan $\mathrm{N}$ tersebut lebih rendah dan nisbah $\mathrm{C} / \mathrm{N}$ yang lebih tinggi dibandingkan dengan kandungan $\mathrm{N}$ dan nisbah $\mathrm{C} / \mathrm{N}$ dalam media dengan bahan seresah daun pinus kasar $\left(\mathrm{A}_{2}\right)$. Kandungan $\mathrm{N}$ tertinggi dan nisbah $\mathrm{C} / \mathrm{N}$ terendah terdapat dalam media dengan bahan daun pinus segar kasar $\left(\mathrm{A}_{3}\right)$, yaitu dengan kandungan $\mathrm{N} 1,00 \%$ dan nisbah $\mathrm{C} / \mathrm{N}$ sebesar 17,24. Kandungan $\mathrm{N}$ dan nisbah $\mathrm{C} / \mathrm{N}$ media meberikan pengaruh yang nyata terhadap pertumbuhan semai. Terdapat hubungan yang positif antara kandungan $\mathrm{N}$ dengan pertumbuhan tinggi dan diameter semai, masing-masing dengan nilai korelasi $(\mathrm{r})=0,64$ dan 0,73 (Gambar 1). Hal sebaliknya ditunjukkan oleh parameter nisbah $\mathrm{C} / \mathrm{N}$ media yang memberikan hubungan negatif terhadap pertumbuhan tinggi dan diameter semai, masing-masing dengan nilai korelasi $(r)=-0,77$ dan $-0,79($ Gambar 2$)$.

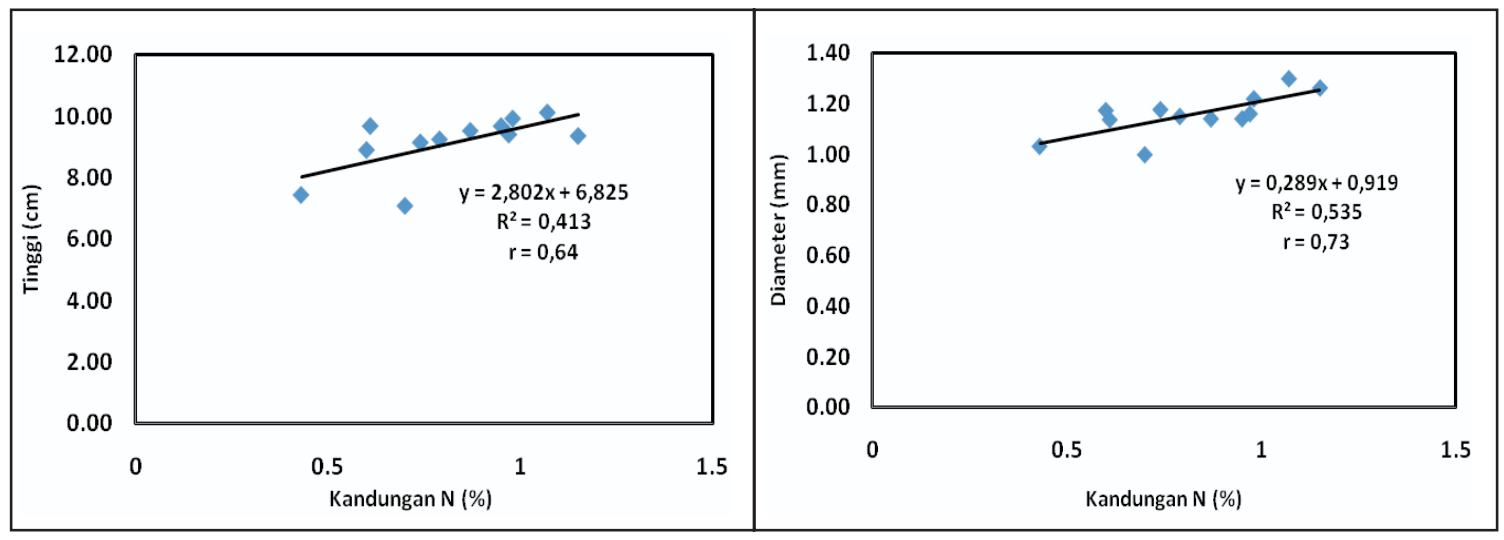

Gambar(Figure) 1. Hubungan antara parameter kandungan $\mathrm{N}$ media dengan pertumbuhan tinggi dan diameter semai (Correlation between $N$ content and $C / N$ ratio of the medium with height and diameter growth of the seedlings)

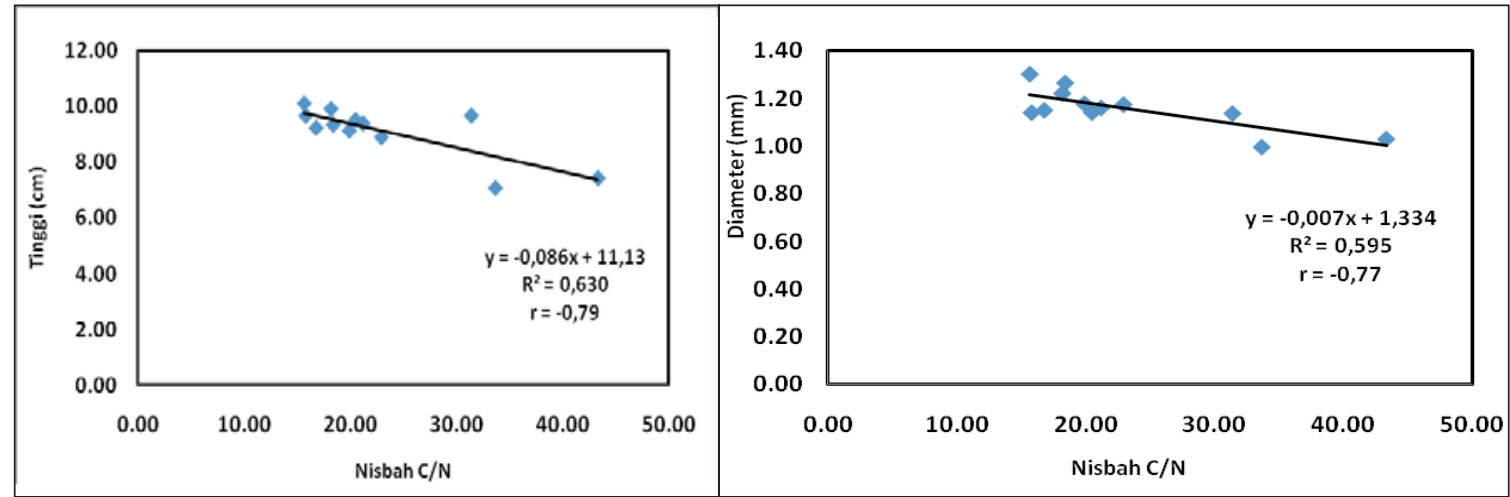

Gambar(Figure)2. Hubungan antara parameter nisbah $\mathrm{C} / \mathrm{N}$ media dengan pertumbuhan tinggi dan diameter semai (Correlation between $C / N$ ratio of the medium with height and diameter growth of the seedlings) 
Bahan media daun memberikan pengaruh yang nyata terhadap pertumbuhan tinggi dan diameter semai pinus. Takeda et al. (1987) melaporkan bahwa beberapa sifat kimia seperti kandungan awal lignin, selulose dan karbohidrat berpengaruh secara nyata terhadap tingkat dekomposisi seresah daun. Tingkat dekomposisi seresah daun dilaporkan berhubungan dengan kandungan awal lignin dan selulose (O'Connel, 1987), dan kandungan awal nitrogen (Melillo et al., 1982). Bahan daun pinus dengan tekstur kasar mempunyai ukuran yang lebih besar memberikan pertumbuhan tinggi dan diameter yang nyata lebih baik dibandingkan dengan yang mempunyai tekstur halus (lebih kecil). Tekstur media kasar dengan ukuran bahan daun yang lebih besar dan tidak mudah terdekomposisi dapat menghasilkan porositas media tumbuh yang lebih besar sehingga aerasinya menjadi lebih baik dan pertumbuhan akar tidak akan mengalami hambatan. Kondisi tersebut dapat mendukung proses metabolisme semai sehingga mampu memberikan pengaruh yang nyata lebih baik terhadap pertumbuhan semai.

Bahan media berupa daun segar kasar ternyata juga memberikan pengaruh pertumbuhan tinggi dan diameter semai yang lebih baik dibandingkan dengan seresah daun kasar. Media dengan bahan daun segar $\left(\mathrm{A}_{3}\right)$ mempunyai kandungan nutrisi $\mathrm{N}$ yang lebih baik daripada seresah daun yang telah tua dan mati. Rauneema et al., (1983) melaporkan bahwa kandungan unsur $\mathrm{N}$ dan $\mathrm{P}$ dalam seresah daun jarum Scots pine jauh lebih rendah dibandingkan dengan daun jarum yang sedang mengalami proses pertumbuhan. Dilaporkan oleh Lim and Cousens (1986) bahwa kandungan unsur hara N, $\mathrm{P}$ dan K dalam daun jarum Scots pine secara umum mengalami penurunan sejalan dengan bertambahnya umur dan mencapai minimum pada saat daun mati. Hardiwinoto et al., (1991) juga melaporkan bahwa kandungan unsur hara $\mathrm{N}$, $\mathrm{P}$ dan $\mathrm{K}$ dalam seresah daun hutan konifer di Jepang Utara jauh lebih rendah dibandingkan dengan kandungan yang ada di dalam daun segar yang sedang dalam proses pertumbuhan.

Kondisi sifat fisik yang baik dengan adanya daun segar kasar dapat mendukung proses penyerapan berbagai unsur hara yang tersedia dalam pupuk organik terutama unsur hara N, P, K yang sangat dibutuhkan oleh semai untuk pertumbuhan. Kramer and Kozlowski (1979) menyebutkan bahwa unsur hara $\mathrm{N}$ mempunyai peranan penting dalam pertumbuhan sel dan perkembangan jaringan meristem batang.
Selanjutnya unsur hara yang lain yaitu fosfor $(\mathrm{P})$ mempunyai peranan penting di dalam pembelahan sel dan perkembangan jaringan merismatik batang (phloem dan xylem) ke arah samping. Menurut Donahue et al., (1977) bahwa pertumbuhan sel-sel dan perkembangan jaringan merismetik ke arah samping ini akan menghasilkan diameter batang lebih besar. Bahan media daun segar kasar $\left(\mathrm{A}_{3}\right)$ telah memberikan pertumbuhan tinggi dan diameter yang terbaik bagi semai pinus.

\section{KESIMPULAN DAN SARAN}

1. Komposisi media yang memberikan tingkat pertumbuhan tinggi dan diameter terbaik semai pinus adalah: 35\% pupuk organik, $35 \%$ tanah bermikorisa dan 30\% seresah daun kasar segar $\left(\mathrm{B}_{2} \mathrm{~A}_{3}\right)$ atau dengan perbandingan sekitar $1: 1: 1$. Komposisi tersebut memberikan rerata pertumbuhan tinggi sebesar 10,12 cm dan diameter sebesar $1,30 \mathrm{~mm}$ yang nyata lebih baik dibandingkan dengan komposisi media $\mathrm{B}_{4} \mathrm{~A}_{1}(15 \% \mathrm{P}+$ $15 \% \mathrm{~T}+70 \%$ daun halus kering) yang mempunyai rerata tinggi sebesar $7,44 \mathrm{~cm}$ dan diameter sebesar $1,03 \mathrm{~mm}$, dan $\mathrm{B}_{3} \mathrm{~A}_{1}(25 \% \mathrm{P}+$ $25 \% \mathrm{~T}+50 \%$ daun halus kering) yang mempunyai rerata tinggi sebesar $7,09 \mathrm{~cm}$ dan diameter sebesar $1,00 \mathrm{~mm}$.

2. Media dengan bahan daun pinus segar kasar $\left(\mathrm{A}_{3}\right)$ mempunyai kandungan $\mathrm{N}$ tinggi dan nisbah $\mathrm{C} / \mathrm{N}$ rendah, serta memberikan pengaruh yang lebih baik terhadap pertumbuhan tinggi dan diameter semai pinus dibandingkan dengan seresah daun $\operatorname{kasar}\left(\mathrm{A}_{2}\right)$ dan seresah daun halus $\left(\mathrm{A}_{1}\right)$.

3. Untuk memproduksi bibit pinus disarankan menggunakan media tumbuh yang terdiri dari pupuk organik, tanah dari bawah tegakan pinus dan daun segar kasar dengan komposisi $35 \%$ pupuk organik, 35\% tanah dan $30 \%$ daun pinus kasar segar $\left(\mathrm{B}_{2} \mathrm{~A}_{3}\right)$.

\section{UCAPAN TERIMA KASIH}

Penulis menyampaikan terima kasih kepada Perum Perhutani Unit I Jawa Tengah yang telah memberikan dukungan dana, saran dan masukan serta kerjasamanya sehingga penelitian ini dapat dilaksanakan dan diselesaikan. Ucapan terima kasih juga kami sampaikan kepada Dr. Ir. Haryono Supriyo, Ir. Adriana, M.P., Pak Jito, 
Pak Heru, dan semua pihak yang telah memberikan bantuan, saran dan masukan dalam pelaksanaan dan penyelesaian penelitian ini.

\section{DAFTAR PUSTAKA}

Baker, F.S. 1950. Principles of Silviculture. Mc, Graw Hill Book Company Inc., New York.

Buckman, H.O. and Brady, N.C. 1969. The Nature and Properties of Soil. The Mac Millan Company, New York.

Butarbutar, T., R.M.S. Harahap dan Paidin, M. 1998. Evaluasi Pertumbuhan Tanaman Pinus merkusii di Aceh Tengah. Buletin Penelitian Kehutanan, Vol. 13 No. 4 Januari 1998. Badan Litbang Kehutanan dan Balai Penelitian Kehutanan (BPK) Pematang Siantar, Sumatera Utara.

Daniel, T.W., Helms, J.A. and Baker, F.S. 1992. Prinsip-prinsip Silvikultur (terjemahan). Edisi kedua Penerbit Universitas Gadjah Mada, Yogyakarta.

Donahue, R. L., Miller, R.W. and Shicluna, J.C. 1977. An Introduction to Soils and Plant Growth, $4^{\text {th }}$ Ed, Prentice-Hall Inc., Englewood Cliffs, New Jersey.

Fakuara, Y. 1988. Mikorisa, Teori dan Kegunaan dalam Praktek. Bogor: PAU IPB, Bogor.

Harahap, R.M.S. 1999. Uji Asal Benih Pinus merkusii di Sumatera Utara. Proseding Seminar Status Silvikultur di Yogyakarta, Tanggal 1-2 Desember 1999, Yogyakarta.

Hardiwinoto, S., Yajima, T. and Igarashi, T. 1991. Stand Structure and Litter Production of Dediduous Broad-Laeved Forest and Evergreen Coniferous Forest in Northern Hokkaido. Res. Bull. Exp. For. Hokkaido Univ. 48 (1): 115-155.

Hardiwinoto, S., Haryono, S., Fasis, M. dan Sambas S. 1994. Pengaruh Sifat Kimia terhadap Tingkat Dekomposisi beberapa Jenis Daun Tanaman Hutan. Manusia dan Lingkungan, Jurnal Pusat Penelitian Lingkungan Hidup Universitas Gadjah Mada No. 4(2) :25-36.

Hardjowigeno, S. 1987. Ilmu Tanah. PT Mediyatama Sarana Perkasa, Bogor.
Kramer, P.J. and Kozlowski, T.T. 1979. Physiology of Woody Plants. Academic Press, New York-London.

Lim, M.T. and Cousens, J.E. 1986. TheInternal Transfer of Nutrient in a Scots Pine Stand (I) Biomass Component, Current Growth and Their Nutrient Content. Forestry 59(1): 1-16.

Melillo, J.M., Aber, J.D. and Muratore, J.F. 1982. Nitrogen and Lignin Control of Hardwood Leaf Litter Decomposition Dynamics. Ecol.63(3): 621-626.

O'Connel, A.M. 1987. Nutrient Dynamics in Decomposing Litter in Karri (Eucalyptus diversicolor F. Muell) Forest of SouthWestern Australia. J. Ecol.76: 1186-1203.

Raunemaa, T., Houtojarvi, A., Samela, J., Erkinjuntii, R., Hari P. and Kellomaki, S. 1983. On Seasonal Variation in the Nutrient Content of Needle from Scots Pine. Can. J. For. Res. 13:365-371.

Rifai, B., Soeroto, S. dan Iskandar, S.P. 1981. Ilmu Memupuk. Penerbit CV Yasaguna, Jakarta.

Russel, E.W. 1973. Soil Conditions and Plant Growth, $10^{\text {th }}$ ed. Longman, London.

Sarief, S. 1986. Kesuburan dan Pemupukan Tanah Pertanian. Cetakan Kedua, Pustaka Buana, Bandung.

Soekotjo. 1977. Pinus merkusii. Bagian Penerbitan Yayasan Pembina Fakultas Kehutanan Universitas Gadjah Mada. Yogyakarta.

Soepardi. 1979. Sifat dan Ciri Tanah II. IPB, Bogor.

Suhardi. 1990. Mikoriza AV. Balai Pengembangan Bioteknologi PAU, Yogyakarta Press, Yogyakarta.

Sutejo, M.M. dan Kartasapoetra, A.G. 1988. Pupuk dan Cara Pemupukan. PT Rineka Cipta, Jakarta.

Sutejo, M.M. dan Kartasapoetra, A.G. 1991. Mikrobiologi Tanah. Rineka Cipta. Jakarta.

Sutejo, M.M. 1992. Pupuk dan Cara Pemupukan. Rineka Cipta. Jakarta. 
Takeda, H., Ishida, Y. dan Tsutsumi, T. 1987. Decomposition of Leaf Litter Relation to Litter Quality and Site Conditions. Mem. Coll. Agric. Kyoto University. 130:17-38.

Tantra, I.G.M. 1981. Flora Pohon Indonesia. Balai Penelitian Hutan, Bogor. 